\title{
Ink for Mettā
}

\author{
墨·映 \\ Joanna To \\ The University of Hong Kong, Hong Kong, China
}

\begin{abstract}
"Ink for Mettā" is the integration of Chinese calligraphy and mettā meditation in the practice of expressive arts therapy. Chinese calligraphy is a traditional form of writing with aesthetic appreciation value, and it is one of the Buddhist meditative practices for enhancing self-awareness. Mettā meditation is a Buddhist tradition of fostering loving kindness with an altruistic view from self toward others. Instead of tackling any emotions or thoughts arising during both practices, we should acknowledge them and return to the present moment of practice. The practices leave room for expressive arts therapy to explore the unattended emotions and thoughts for furthering well-being. The integrative use of Chinese calligraphy and mettā meditation is structured basing on a framework for using art in therapy, expressive therapies continuum. The concepts and applications of "ink for mettā" will be discussed, and the potential for further incorporation of dance and movement therapy will be explored.
\end{abstract}

Keywords: ink, Chinese calligraphy, mettā meditation, expressive arts therapy, Buddhist practice

\section{摘要}

《墨·映》是中國書法和慈心觀在表達藝術治療實踐的結合。中國書法是一種具有美學欣賞 價值的傳統書寫藝術，抄寫經文更是佛教修煉自心覺性的練習。慈心觀是一種佛教傳統修 持，提倡自利利他的精神，培養慈愛。修持旨在提升專注力和覺察，當情緒和念頭生起， 冊須對抗，只要覺察，並回到當下的修習。表達藝術治療正與這種修習相應，在活動的過 程中，讓潛藏的情緒被探視，以至逐漸得到紓解，促進心靈健康。中國書法和慈心觀在表 達藝術治療的實踐，建基於運用藝術於治療中的「表達性治療連續系統」理論架構。本文 將分享《墨·映》的概念和應用，並進一步探討加入舞蹈治療元素的可能性。

關鍵詞：墨，中國書法，慈心觀，表達藝術治療，佛教修持

Chinese calligraphy is a platform for expressing emotions and cultivating inner peace. With the healing functions of Chinese calligraphy, I believe that the creative process can help others nurture holistic health. I am curious to apply Chinese arts with thousands of years of wisdom and heritage for therapeutic use to the practice of expressive arts therapy. The application of expressive arts therapy in the Buddhist setting, together with the Buddhist teachings and practices at the monastery, has enlightened me to consider the integration of Chinese calligraphy and mettā meditation in combination with the expressive therapies continuum, developed by Kagin and Lusebrink for the use in art and expressive psychotherapies since 1978. Moving forward, the incorporation of 
dance and movement therapy concepts into Chinese calligraphy and mettā meditation are to be explored.

\section{Chinese Calligraphy}

The history of Chinese calligraphy dated back as early as in the Shang (商) and Chou (周) periods from the 16th to 10th century $\mathrm{BC}$, when ancient ideograms mainly appeared on oracle bones and bronze containers (Kwo, 1981). There are five main script types, including seal script (篆書), clerical script (隸書), regular script (楷書), running script (行書), and cursive script (草書), all have their unique characteristics besides variations created by different calligraphy masters.

"Different styles of Chinese calligraphy express different personalities and serve for different purpose at different times" (Yu \& Peng, 2005, p. 145). I first learned clerical script, in which each brushstroke is clearly identified and in rectangular shape. The healing impact is the taming of our minds by following one stroke of the character at a time until completing each character. During the process, we can observe how our emotions influence the practice. At the beginning, we may have a sense of agitation, but eventually, we can enjoy peace of mind.

Nevertheless, there are moments when different emotions overwhelm us and disturbing our minds. Chinese calligraphy allows us to express our emotions and feelings through the brush with ink on paper. Huaisu's Autobiography (懷素自敘帖) is a cursive script from calligrapher Huaisu (懷素), who was a master from the Tang Dynasty with a reputation as an alcohol lover. He wrote 〔心手相師」, which means his hands just followed his heart in his Chinese calligraphy (Huaisu, 1997, p. 54). According to Kwo (1981), "From the turnings and moments of that brush one should be able to sense the sentiment being expressed by the artist" (p. 183). In Huaisu's expression, he followed his own rhythm without making any stops between characters. When I copy his work, I simply follow the movement and rhythm of the line without clinging to the details. The process is soothing, and it is the healing function of "energy release and rhythm" at the kinesthetic level according to the expressive therapies continuum (Lusebrink, 1978, p. 398).

The effects of Chinese calligraphy such as physiological slowdown and relaxation as well as heightened attention and concentration have been supported by previous research evidence (Kao, 2006). The psychophysiological effects of practicing Chinese calligraphy include slowed heart rate at a steady rhythm, decreased blood pressure, and decreased respiratory rate (Kao, 1986; Kao, Zhu, Liu, \& Zhang, 2014). In addition, Chinese calligraphy has been proven to have positive effects in patients with posttraumatic stress disorder and nasopharyngeal carcinoma patients, as it reduces hyperarousal symptoms and physiological arousal parameters, respectively (Yang, Li, Hong, \& Kao, 2010; Zhu et al., 2014). The cognitive effects include "quickened response time and improved performance in discrimination and figure identification, as well as enhanced visual spatial abilities, spatial relations, abstract reasoning, and aspects of memory and attention in the practitioners" (Kao, 1995, 2006; Xu, Kao, Zhang, Lam, \& Wang, 2013). 


\section{Mettā Meditation}

Mettā in Pali can be translated as "love" and it is one of the Four Immeasurable Minds practice toward enlightenment in Buddhist teachings (Thich, 2015). Meditation is defined as "a way of being" or "a way of seeing, a way of knowing, even a way of loving" according to Kabat-Zinn (2015, p. 393). Meditation, which is developed from Buddhist teaching and practiced in secular settings, is categorized in three major types including focused-attention meditation, mindfulness or open-monitoring meditation, and compassion or loving kindness meditation (Matthieu, Lutz, \& Davidson, 2014).

Mettā meditation or loving kindness meditation is a "special type of Buddhist meditation that aims to cultivate unconditional kind attitudes toward oneself and others" (Zeng, Chiu, Wang, Oei, \& Leung, 2015, p. 1963). Mettā meditation uses visualization to direct emotions toward warm and tender feelings in an open-hearted way, from self, to sending loving kindness to loved ones, neutral ones, unfriendly ones, and all living beings in the universe (Fredrickson, Cohn, Coffey, Pek, \& Finkel, 2008; Mirisse, 2009).

According to Haynes (2004), "there is growing evidence that meditation, used as a mind-body medicine, is effective alone and as a complement to allopathic medicine in relieving stress, pain, and other physical and mental conditions" (p. 18). In addition, various studies supported that meditation training could reduce anxiety (Fortney \& Taylor, 2010; Miller, Fletcher, \& Kabat-Zinn, 1995). One of the major purposes of meditation practice is to bring us to the present moment with awareness or mindfulness (Baer, 2003). Research evidence also supported the influence of mindfulness from different aspects such as mental health and well-being, physical health, self-regulation, and interpersonal behavior (Brown, Ryan, \& Creswell, 2007; Ludwig \& Kabat-Zinn, 2008).

Although most of the research evidence is centered on mindfulness meditation, there were limited randomized controlled studies evaluating the effects of loving kindness meditation. Hutcherson, Seppala, and Gross (2008) indicated "a few minutes of loving kindness meditation increased feelings of social connection and positivity" and "may help to increase positive social emotions and decease social isolation" (p. 720). Loving kindness meditation "produced increases over time in daily experiences of positive emotions, which, in turn, produced increased life satisfaction and reduced depressive symptoms" (Fredrickson et al., 2008, p. 1045). According to Pace et al. (2009), "Engagement in compassion meditation may reduce stress-induced immune and behavioural responses" (p. 88). Additional studies (pilot study) indicated that loving kindness meditation can help to reduce negative symptoms of schizophrenia, posttraumatic stress disorder, and depression (Johnson et al., 2011; Kearney, Malte, McManus, Martinez, Felleman, \& Simpson, 2013). The results from the pilot study suggested that loving kindness meditation can be "beneficial in reducing pain, anger, and psychological distress in patients with persistent low back pain” (Carson et al., 2005, p. 287).

\section{Buddhist Practices}

"Enlightenment or 'awakening' is a gradual path to wisdom and compassion, achieved by the continual practice of Buddhist teachings" (Tsz Shan Monastery, 2015, p. 48). The daily routine of monastics is scheduled in a highly structured way to facilitate the 
seeking of enlightenment through different meditative practices. Meditative practice can be simply defined as "maintaining a mindfulness throughout your day in everything you do" (Tsz Shan Monastery, 2015, p. 114).

Chinese calligraphy or sutra copying is one of the formal meditation practices. The focus of sutra copying is to enhance our self-awareness at the present moment instead of focusing on the aesthetic of handwriting. The act of sutra copying is regarded as a means of gaining merit, which benefits ourselves and others through transfer of merits (send blessing to others). Sutra copying and mettā meditation are complementary to each other, as they share the intension of radiating loving kindness from self toward the universe.

Impermanence is a core Buddhism concept, and the concept is incorporated in the meditative practices. When we practice sutra copying or mettā meditation, it is unavoidable that emotions, feelings, or thoughts may arise in our minds. The practices train us to "let go of thoughts rather than dwell on them and to focus on and enjoy the present moment" (Tsz Shan Monastery, 2015, p. 114). The meditative practices build the groundwork for self-awareness without tackling any presenting problems. Therefore, the integration of Chinese calligraphy and mettà meditation in combination with expressive arts therapy is to elevate the process for self-actualization.

\section{Navigating the Expressive Therapies Continuum}

Expressive therapies continuum "organizes media interactions into a developmental sequence of information processing and image formation from simple to complex" (Hinz, 2009, p. 4). The framework is arranged in four levels of increasing complexity, and the first three levels comprise bipolar levels of information processing, namely the kinesthetic/sensory, perceptual/affective, and cognitive/symbolic levels (Hinz, 2009). The creative level can be a standalone level or it may integrate the functioning at any or in all levels of the framework (Kagin \& Lusebrink, 1978). The expressive therapies continuum provides information to assess clients' favorite components and significant obstacles to optimal functioning, while facilitating therapists in guiding clients to remove obstacles and increase flexibility through information processing and decision making (Hinz, 2009).

The practice of Chinese calligraphy is a highly structured and complex task engaging both body and mind. At the kinesthetic level, using paint (ink) with brush on paper is a fluid media in which the client can increase or reduce the release of energy through controlling the amount of paint loaded on the brush (Hinz, 2009, p. 43). The sensory interaction with the fluid media can further induce affective experience and navigate to the second level of expressive therapies continuum (Hinz, 2009). "Formal and structural qualities of images" begin to form when marks are made with ink on the paper at the perceptual level, whereas the affective experience induced earlier can further enhance the "expression of emotion and affective images" at the affective level (Lusebrink, 1992, p. 399). Chinese calligraphy requires the functioning at the cognitive level during the creative process. As Kwo (1981) stated, "a piece of calligraphy possesses all the elements of a painting - form, space, line, colour, texture, movement, composition, etc" 
(p. 183). Appreciation and reflection from the Chinese calligraphy leverage the healing dimension of the symbolic component for self-discovery, unlock meanings, and guide personal growth (Hinz, 2009).

The essence of mettā meditation offers insight to enrich expressive arts therapy intervention, as it adds layers of cultivating self-care, thankfulness, forgiveness, and blessing from self toward the universe. Mettā meditation or loving kindness meditation "involves a range of thoughts and visualizations, and it directly evokes only select positive emotions (i.e., love, contentment, and compassion) and carries some potential to evoke negative emotions" (Fredrickson et al., 2008, p. 1045). The focused state of attention toward breathing offers a sensual experience in which "the mind can relax, allowing physical sensations to dominate consciousness" which in turn can "increase awareness of internal calm" (Hinz, 2009, p. 62). Visualization facilitates the formation of images and brings us to the perceptual/affective level. As Hinz (2009) stated, "persons who are overly emotional have been described as being caught up in emotion and unable to see clearly" (p. 8). During the meditation practice, we acknowledge any emotions and feelings without judgement, and embrace ourselves with loving kindness, which in turn can help us to restore an optimal Perceptual/Affective level. Functioning at the Cognitive/Symbolic level is required to take care of our wandering minds.

"Creative information processing can occur at any level and with any component process" (Hinz, 2009, p. 170). One major psychological cause of resistance to create is "self-criticism and fear of criticism by others" (Hinz, 2009, p. 178). Mettā meditation directs our emotions toward "warm and tender feelings in an open-hearted way" (Fredrickson et al., 2008, p. 1046). This helps us reduce our fear to create and to be criticized. Mettā meditation facilitates self-acceptance, whereas any emotions or thoughts can be expressed through Chinese calligraphy.

\section{Application Insights}

In the past four years, Abbot and venerables from the Tsz Shan Monastery have been encouraging me to practice mettā mediation together with Chinese calligraphy. With the support from the monastery's secretary general, I have had the opportunity to launch different expressive arts therapy programs integrating my favorite art form, Chinese calligraphy, with the traditional Buddhist practices.

\section{"A Day of Silence" for caregivers}

Burnout for health-care professionals has brought light to the alarming issue in Hong Kong (Akhtar, Lee, \& Lai, 2006; Chow, 2012). Self-care is an important agenda for health-care professionals because they need to take care of themselves before taking care of their clients. A one-day program was developed to enhance their self-care awareness and reconnect with their body-mind functioning.

In the morning, the program usually begins with walking meditation to engage participants at the kinesthetic level, which "provides feedback about how the body moves in space and a sense of bodily rhythms" (Hinz, 2009, p. 40). As walking meditation is a slow pace movement, it facilitates participants' ability to slow down and get used to 
the monastery environment while activating sensation from the tranquility of nature. To enrich the sensory experience, each participant walks with a pebble in his or her hands to feel the weight, temperature, and texture and to observe any changes when moving between indoor and outdoor venues. Pebble painting will follow to evoke any image formation at the perceptual level. Participants may have affects aroused during the process or have a better self-understanding at the cognitive level.

In the afternoon, Chinese calligraphy is used to facilitate the connection between body and mind. As warmup, participants are invited to use their body as brush and paint on the air to engage them at the kinesthetic level. Participants then transform the movement with the brush and ink on paper. The aesthetic of viewing Chinese calligraphy is "being conscious of the artist's sentiment and feelings at the time when he was creating his work" (Kwo, 1981, p. 183).

Two different styles of script samples are provided to participants for copying, including a seal script and a cursive script, which engage them at the cognitive level. The contrast between the two scripts provides participants the opportunity to observe their pattern in handling the creative process. In different groups, participants associate the seal script copying process to their work pattern. The seal script characters are clearly described, and participants can follow stroke by stroke, similar to following protocols and procedures at work. The cursive script is a challenge for participants, as they could barely read the writing. Most of them initially have a brief struggle, but they soon enjoy the process of creating their own calligraphy with reference to the sample. They manage to let go of their usual working pattern and enjoy the creative process. Participants are asked to paint a Zen circle "with one brushstroke, in a single breath," which connects body and mind and reflects the mind of participants at the present moment (Seo, 2009, p. xii). Upon completing the circle, participants are invited to take a couple minutes to contemplate on their circles and write down any words or phrases that come across their mind at the symbolic level.

In concluding the day program, metta meditation is introduced with the intention of reinforcing the insight generated as the key take-away from the program while sharing the joy of having a day of silence to others. There were touching moments when participants appreciated the space for self-care and shared how they would apply and share the experience with others in daily life. The altruistic perspective of loving kindness from self-care radiating to others speaks the essence of mettā meditation.

\section{Alternative Chinese calligraphy for youths in Hong Kong}

The expressive arts intervention is to offer a different experience of using Chinese calligraphy for youths to express and connect with others while leveraging the healing dimensions of the expressive therapies continuum in day programs and youth camps.

"The healing dimension of the kinesthetic components of the ETC involves increasing or decreasing clients' amount of arousal and tension" (Hinz, 2009, p. 41). Working with youth at the kinesthetic level can facilitate them to reduce tension and attune to the group atmosphere by discharge of energy. Water-writing cloths (水寫布) are used for participants to physically move along the cloth and paint with brushes and 
water, let their emotions and energy, vent or even create chaos in such a safe platform. When we paint with water on the cloths, brush strokes will appear like ink on paper and they will disappear when the water evaporate.

After the warmup, proper Chinese calligraphy materials including rice paper, brush, and ink are used. Ink requires more control and skills to handle and makes permanent marks on the rice paper, and it may create uncleanable mess. With the media challenge, participants will experience limitation and boundary while focusing on the "perceptual or form qualities of the expressive experience" (Hinz, 2009, p. 83). Group creative process is introduced to work with the cognitive/symbolic components when participants have to "plan activities, negotiate issues, or solve problems together" (Hinz, 2009, p. 247). Participants are required to hold the strings connecting to a brush and create the calligraphy as a team (Figure 1). Alternatively, each participant is allowed to paint one stroke on the paper in order to create group art (Figure 2). Hinz (2009) defined the healing dimension of the creative level of the expressive therapies continuum "as inventive and resourceful interaction with the environment leading to creative selfactualizing experiences" (p. 171). From participants' reflections, the group activities facilitated them to establish order out of chaos. They struggled on their own ways but eventually became aware of the group needs to complete the task and understand the

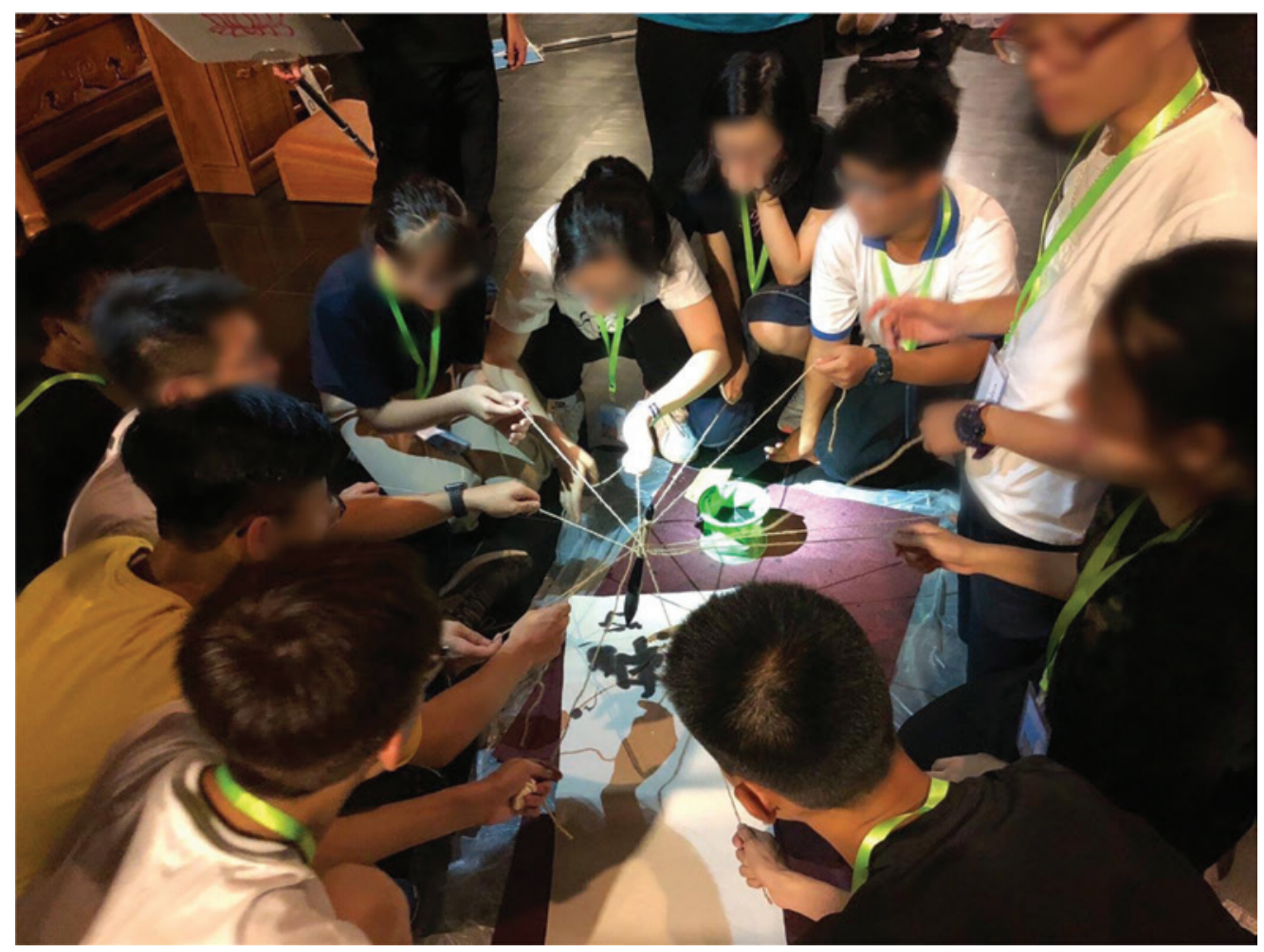

FIGURE 1 | Group Chinese calligraphy using strings to control the brush. 


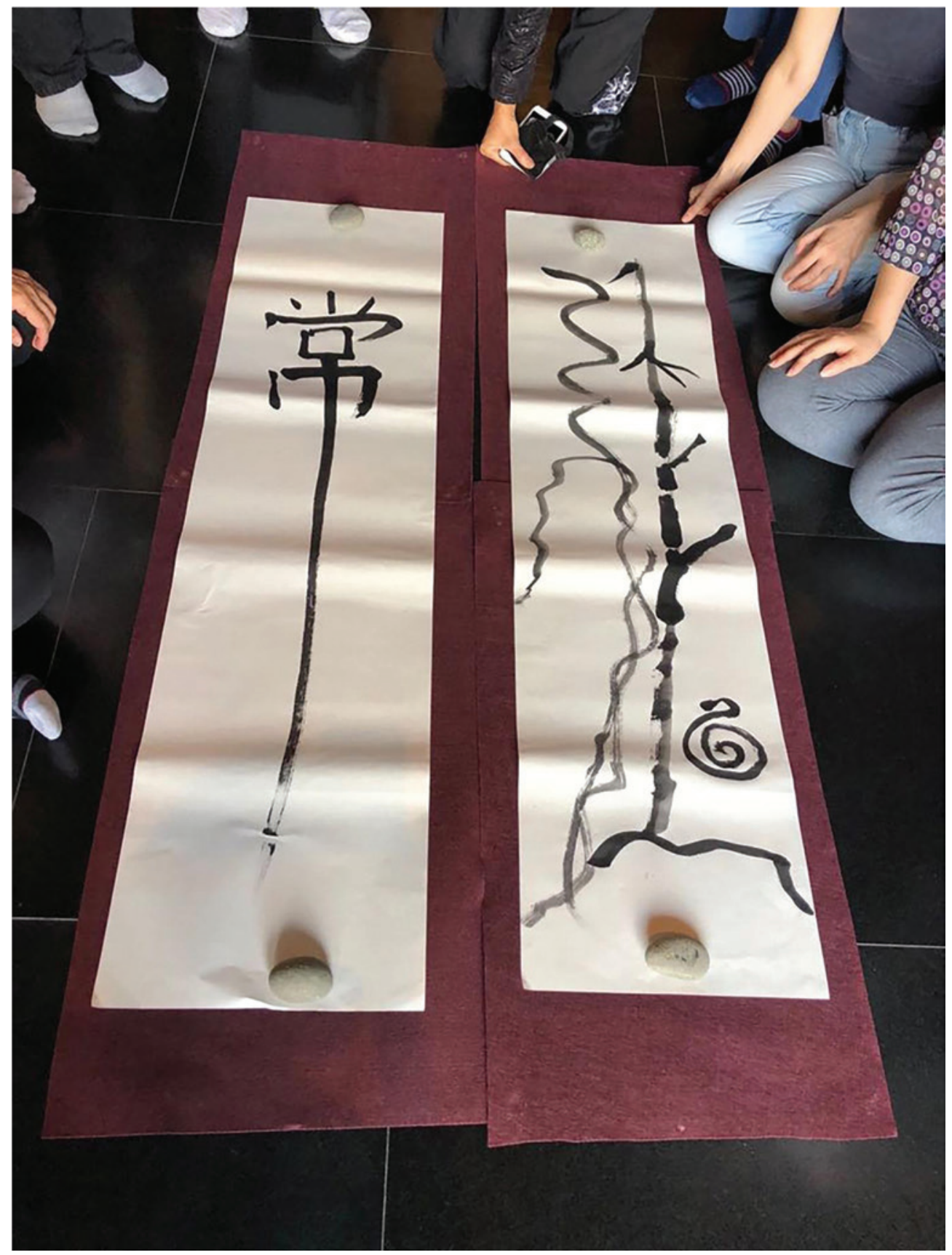

FIGURE 2 | Group Chinese calligraphy with one stroke per person.

altruistic perspective in team work. They felt wholeness and satisfaction from the group creative art. The group calligraphy helped them to crystallize the team work process in which they could bring back to daily work. 
Mettā meditation is used as closing activity aiming to strengthen self-awareness on body-mind connection and explore inner resources. The meditation process creates personal space to get in touch with inner feelings and synthesis with the program experience, from easy handling of water on water-writing cloth to using ink on rice paper and from individual work to group work. At the cognitive/symbolic level, it is important for them to reflect and discover personal meaning from the process. The healing function at the symbolic level is "the discovery of new, previously unknown, and unavailable facets of the self and the integration of this knowledge into new sense of self" (Hinz, 2009, p. 157).

\section{Chinese calligraphy connections with international conference participants}

I had the opportunity to share the experience of using Chinese calligraphy and mettā meditation at the ANZACATA Perth Conference in 2018. As Chinese calligraphy may not be a familiar art media for the international participants, I started the workshop with a short video clip on a dance performance by the Cloud Gate Dance Theatre of Taiwan to give a different perspective of Chinese calligraphy. Instead of using brushes, ink, and paper to write, dancer used their bodies as brushes to express the movement of Chinese calligraphy on stage. The video facilitated the activation of the kinesthetic components as the movements of the participants could be witnessed while watching the video. The workshop design was a highlight version of "A Day of Silence" program due to time constraint. We had line practice with water and ink, mettā meditation, and Zen circle painting. The objective of the workshop was to provide an experience of using traditional Chinese art for connecting body-mind functioning.

My major concern of introducing Chinese calligraphy to the target audience is language barrier because Chinese is not a universal language. I invited participants to write a simple Chinese character for "heart” (心) together. The process went smoothly, and participants managed the lines and spacing to create the character. Participants requested to write the Chinese character for "love" (愛). I spontaneously replied, "love is complicated," in reference to the complicated Chinese character, but it could also refer to the nature of love, which let to laughter. After practicing the two Chinese characters, we had mettā meditation prior to painting a Zen circle. The mediation practice allowed a few minutes for participants to contemplate the new experience with Chinese calligraphy, connecting their heart to the concept of loving kindness from self to others. After the meditation, we created our own Zen circle to symbolize wholeness. Participants were invited to write a word in any language to remember the workshop experience. Majority of them wrote "love" in Chinese inside the circle (Figure 3). The insight for myself was that the use of Chinese calligraphy should not be limited by the language itself because art is a universal language to communication.

\section{Way Forward}

"Ink for Mettā" can further incorporate dance and movement therapy concepts to strengthen the process. The inspiration comes from the performance by the Cloud Gate 


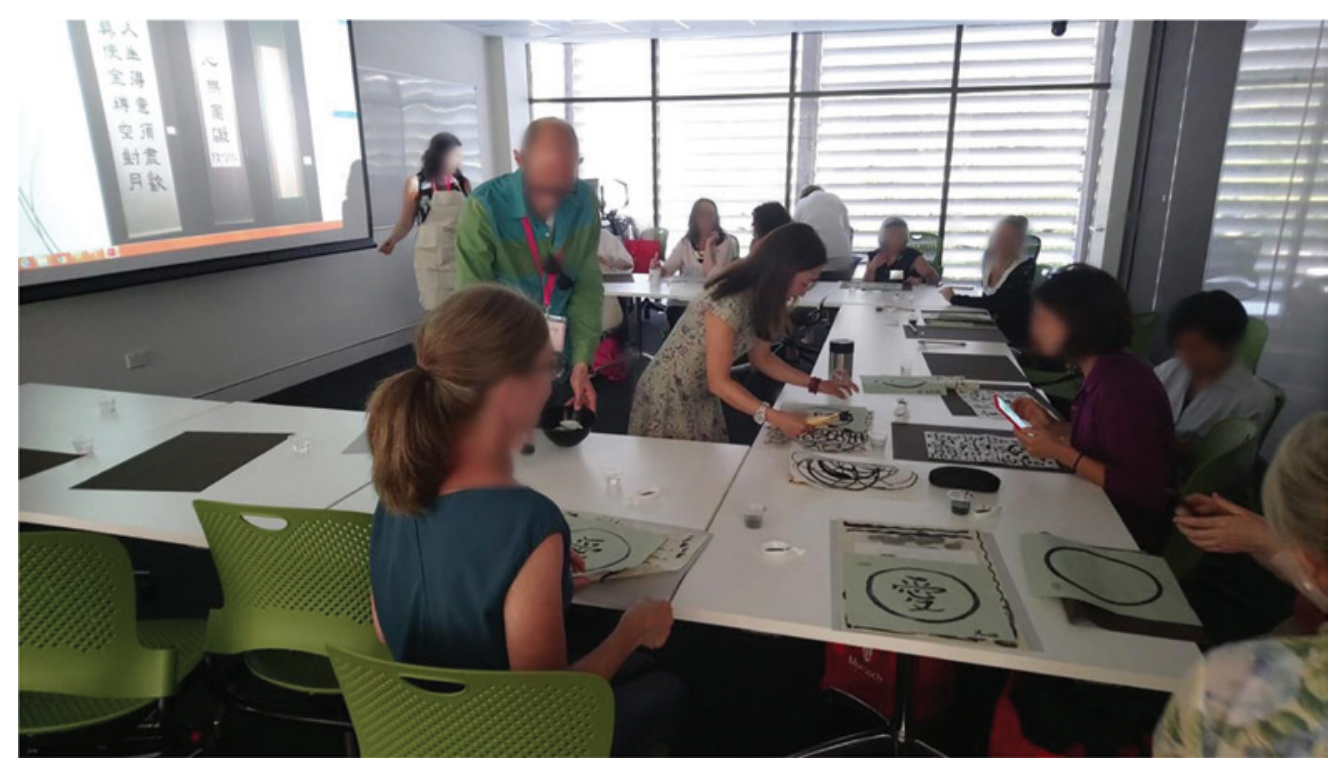

FIGURE 3 | Zen circle with Chinese character '愛” (love) in the middle.

Dance Theatre of Taiwan. Dancers use body movement to create Chinese calligraphy on stage, and there is potential to transform the movement on paper.

Chinese calligraphy engages the use of brush through our body movement from the movement of the fingers and palm to hold the brush, to the movement of our wrists, arms, and upper body with grounding support from the lower body to make lines on paper. The paper acts like a mirror and reflects our movement. In Chace's techniques, mirroring is "reflect[ing] back via her own muscular activity and verbal narration what she perceived and experienced in the body action and the body of the patient ... Mirroring of action and meaning, also referred to as kinesthetic empathy or empathetic reflection" (Levy, 2005, p. 24). Instead of having a partner to mirror our movement, the movement is reflected in our Chinese calligraphy. According to Richardson et al. (2011), "when the mark is made on paper, it is very easy to see the power and direction of movement" (p. 72-73). Laban Movement Analysis can be deployed to examine the motion changes from the Chinese calligraphy. It is a systemic approach in describing changes in movement in terms of 'effort'. "Effort describes movement dynamics in terms of four motion factors: space, weight, time and flow" (Levy, 2005, p. 110). The movement changes can be observed through the amount of ink, thickness and smoothness of lines, pauses or stops, turns, etc., which are signs for us to reflect on the process and explore the attribute for the changes.

"Body movement reflects inner emotions states and that changes in movement behaviour can lead to changes in the psyche, thus promoting health and growth" (Levy, 2005 , p. 1). In a nutshell, incorporating dance and movement therapy concepts together with Chinese calligraphy not only offers a record for movement analysis, but it can also amplify the creative process by connecting with our inner self. 


\section{Conclusion}

This paper consolidates the learnings, explorations, and applications of expressive arts therapy in the Buddhist setting. It has been a meaningful journey from the use of Chinese calligraphy as a media for use in expressive arts therapy to having an expanded perspective and to the integration of expressive arts therapy in combination with meditative practices.

Chinese calligraphy has a long tradition not only for the aesthetic quality and appreciation but also for nurturing one's noble character (修養). Unfortunately, most people do not have interest and time for Chinese calligraphy practice due to advances in technology and the fast-paced living in Hong Kong. On the contrary, meditation is becoming fashionable in the search for the tranquility of the mind. The application of expressive arts therapy at the monastery has allowed me to rediscover the healing function of Chinese calligraphy with meditative practices together with program participants. The limitations include lack of research in examining the benefits of using Chinese calligraphy together with meditative practices in the expressive arts therapy field. Besides, the lack of formal training in mettā meditation has imposed limits to fully integrate the practice with expressive arts therapy. Further understanding on the philosophy and practice will definitely further enhance the integration and therapeutic effects.

Hong Kong has been experiencing a long drawn-out protest since June 2019. Furthermore, with the recent coronavirus outbreak, the city has been filled with negative emotions such as fear, anger, sadness, resentment, and so forth. Under such circumstance, I sincerely hope the therapeutic use of "Ink for Mettā" in the practice of expressive arts therapy can offer a way to rediscover inner peace and promote the spirit of mettā in order to rebuild harmony in family and society. As for the closing, here is the highlight from Mettā Sutra 《慈經》(Salzberg, 1995):

So with a boundless heart

Should one cherish all living beings;

Radiating kindness over the entire world:

Spreading upwards to the skies,

And downwards to the depths;

Outwards and unbounded,

Freed from hatred and ill-will.

讓無限的慈心遍照於十方世界，上下左右，不受阻擾，不懷仇恨，不抱敵意。

\section{Acknowledgment}

I would like to express my deepest thanks to my family and mentors. Having you as witnesses on the positive impacts of arts on me is the most powerful support on my journey as an expressive arts therapist. I dedicate this work to the Venerable Thong 
Hong, the abbot of Tsz Shan Monastery, and Mr. Walter Ngai, the secretary general of Tsz Shan Monastery, who have provided me with ample opportunities and support in applying expressive arts therapy in the monastery.

\section{About the Author}

Joanna To, AThR, REAT, MExpArtsTh, MBA, MA, BA (Hon), is a registered arts therapist, a certified Zentangle and Pastel-Nagomi-Art teacher, and a chartered marketer. She has worked with different populations in schools, corporations, elderly homes, youth centers, and Buddhist monastery in Hong Kong. She is passionate in integrating Chinese art and meditative practices under the domain of expressive arts therapy and in helping others nurture holistic health. Joanna used to work in corporate settings as a communications professional for over 15 years prior to pursuing a career as an arts therapist. The experience will be the cutting edge in her future therapist endeavors.

\section{References}

Akhtar, S., Lee, J., \& Lai, J. (2006). Sources, coping mechanisms, and consequences of burnout among nurses in Hong Kong public hospitals: implications for human resource management practices. Hong Kong Medical Journal, 12(Suppl. 1), 35-38.

Baer, R. (2003). Mindfulness training as a clinical intervention: A conceptual and empirical review. Clinical Psychology: Science and Practice, 10(2), 125-143.

Brown, K., Ryan, R., \& Creswell, J. (2007). Mindfulness: Theoretical foundations and evidence for its salutary effects. Psychological Inquiry, 18(4), 211-237.

Carson, J., Keefe, F. J., Lynch, T. R., Carson, K. M., Goli, V., Fras, A. M., \& Thorp, S. R. (2005). Loving- kindness meditation for chronic low back pain: Results from a pilot trial. Journal of Holistic Nursing, 23(3), 287-304.

Chow, C. (2012). Satisfied patients, burnout doctors! Hong Kong Medical Journal [Xianggang Yi Xue Za Zhi], 18(5), 360-361.

Mirisse, D. (2009). Stress reduction for youth through mindfulness and loving-kindness meditation. Sri Lanka: Buddhist Cultural Centre.

Fortney, L., \& Taylor, M. (2010). Meditation in medical practice: A review of the evidence and practice. Primary Care: Clinics in Office Practice,37(1), 81-90.

Fredrickson, B., Cohn, M., Coffey, K., Pek, J., \& Finkel, S. (2008). Open hearts build lives: Positive emotions, induced through loving-kindness meditation, build consequential personal resources. Journal of Personality and Social Psychology, 95(5), 1045-1062.

Haynes, A. (2004). Meditation and health: An annotated bibliography. Reference \& User Services Quarterly, 44(1), 18-25.

Hinz, L. (2009). Expressive therapies continuum: A framework for using art in therapy. New York, NY; London: Routledge.

Huaisu. (1997). Five kinds of Huaisu cursive script. Tianjin: Tianjin Ancient Books Publishing House.

Hutcherson, C., Seppala, E., \& Gross, J. (2008). Loving-kindness meditation increases social connectedness. Emotion, 8(5), 720-724.

Johnson, D., Penn, D., Fredrickson, B., Kring, A., Meyer, P., Catalino, L., \& Brantley, M. (2011). A pilot study of loving-kindness meditation for the negative symptoms of schizophrenia. Schizophrenia Research, 129(2-3), 137-140.

Kabat-Zinn, J. (2015). Meditation — it's not what you think. Mindfulness, 6(2), 393-395.

Kagin, S. L., \& Lusebrink, V. B. (1978). The expressive therapies continuum. Art Psychotherapy, 5(4), $171-180$. 
Kao, H. (1986). Shu fa xin li xue. Taibei Shi: Dong da tu shu gon si.

Kao, H. (1995). Shu fa yu ren zhi. Taibei: Dong da tu shu gu fen you xian gong si.

Kao, H. (2006). Shufa: Chinese calligraphic handwriting $(\mathrm{CCH})$ for health and behavioural therapy. International Journal of Psychology, 41(4), 282-286.

Kao, H., Zhu, L., Liu, I., \& Zhang, M. (2014). Calligraphy and meditation for stress reduction: An experimental comparison. Psychology Research and Behavior Management, 7, 47-52.

Kearney, D., Malte, C., McManus, C., Martinez, M., Felleman, B., \& Simpson, T. (2013). Loving- kindness meditation for posttraumatic stress disorder: A pilot study. Journal of Traumatic Stress, 26(4), 426-434.

Kwo, D. (1981). Chinese brushwork: Its history, aesthetics, and techniques. Montclair, NJ: Allanheld \& Schram.

Levy, F. J. (2005). Dance movement therapy: A healing art. Reston, VA: National Dance Association and Association of the American Alliance for Health, Physical Education, Recreation, and Dance.

Ludwig, D., \& Kabat-Zinn, J. (2008). Mindfulness in medicine. JAMA, 300(11), 1350-1352.

Lusebrink, V. B. (1992). A systems oriented approach to the expressive therapies: The expressive therapies continuum. Arts in Psychotherapy, 18, 395-403.

Matthieu, R., Lutz, A., \& Davidson, R. J. (2014). Mind of the meditator. Scientific American, 311(5), $38-45$.

Miller, J. J., Fletcher, K., \& Kabat-Zinn, J. (1995). Three-year follow-up and clinical implications of a mindfulness meditation-based stress reduction intervention in the treatment of anxiety disorders. General Hospital Psychiatry, 17(3), 192-200.

Pace, T. W., Negi, L. T., Adame, D. D., Cole, S. P., Sivilli, T. I., Brown, T. D., Issa, M. J., \& Raison, C. L. (2009). Effect of compassion meditation on neuroendocrine, innate immune and behavioral responses to psychosocial stress. Psychoneuroendocrinology, 34(1), 87-98.

Richardson, J. F., Gollub, A., \& Wang, C. (2012). Inkdance: Body, mind and Chinese medicine as sources for art therapy. In Art Therapy in Asia: To the bone or wrapped in silk. London; Philadelphia, PA: Jessica Kingsley Publishers.

Salzberg, S. (1995). Lovingkindness: The revolutionary art of happiness. Boston, MA: Shambhala.

Seo, A. Y. (2009). Enso: Zen circles of enlightenment. Boston, MA: Weatherhill.

Tsz Shan Monastery. (2015). Tsz Shan Monastery: A journey into clam. Hong Kong: Tsz Shan Monastery Limited.

Thich, N. H. (2015). The heart of the Buddha's teaching: transforming suffering into peace, joy and liberation. New York: Harmony Books.

Xu, M., Kao, H., Zhang, M., Lam, S., \& Wang, W. (2013). Cognitive- neural effects of brush writing of Chinese characters: cortical excitation of theta rhythm. Evidence-Based Complementary and Alternative Medicine, 2013, 11.

Yang, X. L., Li, H. H., Hong, M. H., \& Kao, H. S. (2010). The effects of Chinese calligraphy handwriting and relaxation training in Chinese nasopharyngeal carcinoma patients: A randomized controlled trial. International Journal of Nursing Studies, 47(5), 550-559.

Yu, J., \& Peng, Q. (2005). Realistic synthesis of cao shu of Chinese calligraphy. Computers \& Graphics, 29(1), 145-153.

Zeng, X., Chiu, C., Wang, R., Oei, T., \& Leung, F. (2015). The effect of loving-kindness meditation on positive emotions: A meta-analytic review. Frontiers in Psychology, 6, 1693.

Zhu, Z., Wang, R., Kao, H., Zong, Y., Liu, Z., Tang, S., \& Lam, S. (2014). Effect of calligraphy training on hyperarousal symptoms for childhood survivors of the 2008 China earthquakes. Neuropsychiatric Disease and Treatment, 10, 977-985. 